\title{
Mecanismos da construção federal da intersetorialidade no Programa Bolsa Família: o papel das burocracias
}

\author{
Lucas Ambrózio Lopes da Silva
}

\section{Introdução}

As recentes políticas de desenvolvimento social promovidas no Brasil são marcadas por grandes desafios, e têm tensionado a estrutura estatal a responder segundo novos arranjos, exigindo processos de experimentação institucional e novas formas de coordenação entre os setores governamentais (SILVA, 2011). Esse contexto é marcado pela constatação de que a intersetorialidade tem sido disseminada como uma tarefa compartilhada entre os governos nacionais e subnacionais. Isso possibilita novas formas de coordenação governamental, com a finalidade de integração dos serviços públicos, ofertando políticas públicas que consigam atacar problemas estruturais, como é a questão da pobreza.

O objetivo deste artigo é descrever e analisar os mecanismos pelos quais a intersetorialidade é construída no Programa Bolsa Família (PBF) no nível federal. Embora a tarefa de conferir intersetorialidade ao programa seja compartilhada entre União e Municípios, principalmente, este trabalho enfocará a dinâmica de 
ação do Governo Federal, procurando entender como este tem construído suas estratégias de intersetorialidade. Partimos do pressuposto de que a literatura apresenta um importante acúmulo analítico da intersetorialidade no Programa Bolsa Família, compreendendo seus programas complementares e a atuação dos Municípios (CARNEIro et al., 2010; NAVARro 2011; Quinhões e FAVA, 2010). No entanto, faltam estudos que entendam o processo de construção incremental dessa intersetorialidade, incluindo os trabalhos dos ministérios do Executivo Federal e o papel dos fluxos de poder e de engajamento das burocracias federais.

A hipótese levantada é de que o PBF construiu em nível federal importantes mecanismos de intersetorialidade, orientados por processos de alta concentração de recursos políticos e técnicos. Esses mecanismos, combinados de maneira estratégica, fariam da coordenação intersetorial exercida no PBF um caso significativo de alto grau de intersetorialidade. Assim, busca-se trazer luz sobre perguntas do tipo: quais foram os mecanismos de intersetorialidade desenvolvidos para o PBF no Governo Federal? Qual o papel das lideranças políticas e dos fluxos de poder? Qual foi a estratégia burocrática adotada? Qual o papel exercido pelos burocratas responsáveis pelo PBF?

Utilizou-se como uma das técnicas de pesquisa adotadas a análise documental: de leis, diretrizes, relatórios, dados do sistema de condicionalidades, bem como das portarias interministeriais e normas operacionais. A partir desse levantamento, pode-se ter um importante dimensionamento dos instrumentos institucionais formais de construção da intersetorialidade, insuficiente, no entanto, para se entender a materialização e operação das dinâmicas informais que impactam nas formas e forças da intersetorialidade alcançada.

Foi com o intuito de complementar a análise das dinâmicas operacionais e informais que utilizamos a técnica de entrevistas qualitativas. Foram entrevistados representantes de diversas áreas do Ministério do Desenvolvimento Social e Combate à Fome (MDS). Entrevistamos seis dirigentes envolvidos no PBF, representando a Secretaria Nacional de Renda de Cidadania (Senarc/MDS), bem como os seus quatro departamentos, além da Secretaria Extraordinária de Combate à Extrema Pobreza (SESEP/MDS). As perguntas realizadas foram sobre temas relativos à materialização da construção da intersetorialidade, a oposição entre dinâmica formal e informal, o papel das lideranças e dos fluxos de poder, além de deixar espaço para que o entrevistado pudesse destacar os elementos que julgasse mais significativos para a construção de um ambiente de coordenação intersetorial. Tal análise foi feita tomando as declarações dos entrevistados e cotejando-as com a literatura sobre burocracia e política e com dados e informações coletados na pesquisa documental.

Ao longo do artigo, apresentar-se-ão mecanismos organizacionais e estratégias políticas mobilizados com distintas consequências sobre o grau da instersetorialidade construída. Assim, fica nítido que a atuação do Governo Federal, no que diz respeito ao tema, vai muito além da formulação e do lançamento das diretrizes para o programa. A construção da intersetorialidade teria contado, principalmente, com importantes mecanismos de politização e empoderamento da burocracia, o que fez emergir o protagonismo de uma burocracia de nível médio (ou intermediário), com alta qualificação técnica e com 
importantes capacidades de articulação, seja com outros burocratas, seja com o corpo político.

Não há como ir adiante sem lançar mão das problemáticas ao redor da intersetorialidade e esclarecer o que entendemos como tal. Cunill Grau (2005) argumenta acerca de duas problemáticas existentes nos estudos sobre intersetorialidade, com base na origem da justificativa proposta por eles (mais política ou mais técnica). A premissa mais política é a de que a integração entre setores possibilita a busca de soluções integrais aos problemas sociais e se traduz na ideia de que todas as políticas públicas que persigam estratégias globais de desenvolvimento, como a melhoria da qualidade de vida da população, devem ser planejadas e executadas intersetorialmente. Já a premissa mais técnica concentra seu foco sobre a análise da eficiência, afirmando que a integração entre os setores permite que as diferenças entre eles possam ser usadas produtivamente no enfrentamento dos problemas sociais, por criar melhores soluções que a setorialidade, já que permite compartilhar os recursos (não somente econômicos, mas das mais distintas ordens) que são próprios de cada setor. Desse modo a intersetorialidade ganha destaque para se superar o que Martins (2005) descreve como sendo a existência de uma "teoria da fragmentação" no que diz respeito à formulação/implementação das políticas públicas.

O conceito utilizado neste trabalho levou em conta a análise tanto de trabalhos que envolvem a temática da intersetorialidade, como de trabalhos que desenvolvem a problemática em torno da coordenação governamental, forjando um novo conceito a partir da junção desses dois âmbitos de estudo (BAKVIs, 2004; Bourgault, 2002; Carneiro, 2010; Cunill
Grau, 2005; Guirado, 2008; Martins, 2005; Peters, 1998; Repetto, 2009; SERrA, 2004). O conceito aqui utilizado de intersetorialidade é:

(...) conjunto de desenhos formais e práticas que conferem sinergia e complementaridade entre as diversas áreas específicas das políticas sociais, como assistência social, educação, saúde, etc, bem como entre os diversos

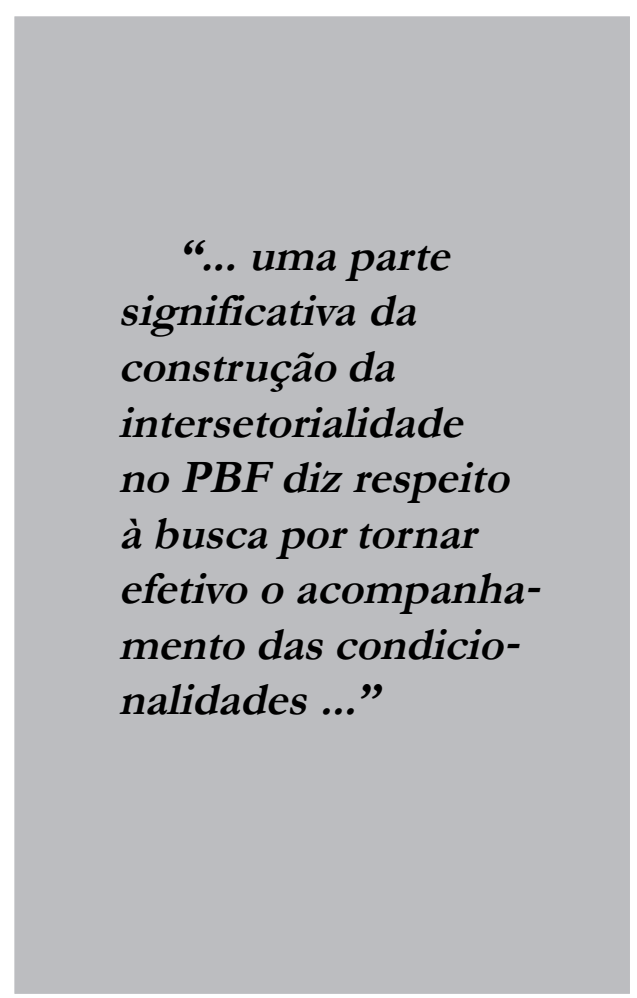

setores engajados na produção das políticas públicas (como o administrativo, o orçamentário, o de planejamento, de recursos humanos, etc.) (Silva, 2011, p.2).

Recentemente as políticas de desenvolvimento social no Brasil têm emergido articulando as estratégias de desenvolvimento 
com as políticas sociais. Tal orientação trouxe fortes desafios para o Estado brasileiro. O Programa Bolsa Família sintetizaria essa nova tendência e essa nova forma com que o Estado tem atuado para dar maior dinamismo às políticas públicas, calcada na criação de órgãos que perseguem claros objetivos de políticas sociais e diminuição de desigualdades, e que têm na coordenação intersetorial uma de suas missões mais fundamentais ${ }^{1}$. A intersetorialidade seria um princípio emergente, dadas as orientações políticas recentes e o cenário de grande fragmentação da atuação estatal e de suas instituições, que leva a um conjunto desarticulado de políticas públicas. A intersetorialidade é, pois, um princípio tão necessário como emergente para esse processo de convergência das estratégias econômicas e sociais (SILVA, 2013). Ela é, também, um dos princípios do PBF, constituindo-se, fortemente, em relação às condicionalidades do programa e dos programas complementares, pressupondo um compromisso entre Estado e sociedade para a ampliação da oferta e acesso a serviços públicos.

O Programa Bolsa Família foi criado em 2003, a partir da unificação dos programas Bolsa Escola, Bolsa Alimentação, Cartão Alimentação e Auxílio Gás, como forma de implementação de um corpo de políticas sociais altamente distributivas e focalizadas (CARneIro, 2010; Neri, 2008). É um programa de transferência direta de renda com condicionalidades de educação, saúde e assistência social. Os valores transferidos são definidos com base na renda mensal per capita da família e também no número de crianças e adolescentes até 17 anos. O Cadastro Único é um dos instrumentos de gestão do programa que possibilita o cadastro e acompanhamento das famílias inscritas no programa.
O Cadastro Único foi criado no governo do Presidente Fernando Henrique Cardoso, muito embora ainda sem a unificação dos sistemas, e tinha um cenário de ações sobrepostas e fragmentadas como obstáculo. Naquele período, o cadastro era fortemente restrito ao Programa Bolsa Escola e era gerenciado pelo Ministério da Educação. Hoje o Cadastro Único gerencia de maneira descentralizada diversas informações socioeconômicas das famílias inscritas, sendo utilizado para inúmeros programas dos governos federal, estaduais e municipais e indo além das famílias do PBF. São mais de 25 milhões de famílias inscritas, sendo um grande censo da pobreza no Brasil. É, portanto, per si um importante mecanismo de intersetorialidade, constituindo-se como o grande corpo de tecnologia de informação que sustenta e potencializa as ações intersetoriais.

\section{A construção federal da interse torialidade no PBF}

Uma das características centrais do PBF é a forte articulação federativa que ele demanda, dada a sua missão: ser um programa nacional que consiga transferir renda e gerir suas condicionalidades em todas as localidades, por mais distantes que sejam. Como modo de gerar um mecanismo de incentivo à cooperação com Estados e Municípios, foram criados diversos mecanismos, como o Índice de Gestão Descentralizada - IGD (BICHIR 2011), que transfere recursos aos Estados e Municípios mediante o cumprimento de alguns quesitos e o alcance de diversos parâmetros. Assim, uma boa parte das diretrizes e decisões tomadas em nível federal tem grande impacto sobre os entes federativos, tanto diretamente quanto indiretamente, induzindo-os a alcançarem determinados 
indicadores. Não entraremos aqui nas discussões sobre os impactos dos mecanismos de coordenação federativa envolvidos no $\mathrm{PBF}$, que não são consenso na literatura, nem são o objeto deste artigo.

Para além dos referidos impasses sobre o impacto dos arranjos federativos construídos no PBF, é consenso que nesse programa o Governo Federal teve um forte papel de transformação da forma de atuação local e desenvolveu mecanismos institucionais para assegurar um forte poder de agenda e de planejamento do programa. Sendo assim, o que se passa no Governo Federal, embora seja insuficiente para entender ou explicar as características da implementação do programa por todo o território nacional, é importante para entendermos os elementos políticos centrais e as estratégias de coordenação experimentadas desde a formulação da política. Lançar luz sobre os mecanismos formais, a dinâmica dos fluxos de poder e a atuação das burocracias federais de Brasília (muitas vezes invisíveis numa política tão capilarizada pelo território nacional), no processo de construção de intersetorialidade, é tão revelador quanto instigante.

Para melhor entender tais processos, devem ser apresentados outros mecanismos que geram intersetorialidade no PBF. Além dos mecanismos que serão analisados adiante, pode-se destacar o papel do Cadastro Único e dos programas complementares ao $\mathrm{PBF}$, geridos tanto pelo Ministério do Desenvolvimento Social e Combate à Fome (MDS), quanto por outros ministérios. De fato, o Cadastro Único tem ampliado a capacidade de diálogo e coordenação do PBF com outros programas de outras áreas, principalmente com a criação do Plano Brasil Sem Miséria (PBSM) em 2011. Assim, o PBF passa a assumir o papel de eixo central da política de combate à miséria e o MDS passa a coordenar ações de diversos setores, envolvendo mais de oito ministérios.

No caso do PBF, também não se pode deixar de mencionar a intersetorialidade que advém das condicionalidades, fundamentalmente de educação e saúde. Já a condicionalidade de assistência social, criada, posteriormente, a partir da incorporação do antigo Programa de Erradicação do Trabalho Infantil (Peti), e que diz respeito ao acompanhamento das famílias com alta vulnerabilidade ao trabalho infantil, não é um consenso, já que o seu acompanhamento ainda não é uma prática sistemática, não constando sequer no Sistema de Condicionalidades do Programa Bolsa Família (Sicon). Desse modo, uma parte significativa da construção da intersetorialidade no PBF diz respeito à busca por tornar efetivo o acompanhamento das condicionalidades, envolvendo mecanismos de coordenação com a política de inclusão escolar e com a política de atenção básica em saúde.

Formalmente, um dos mecanismos de coordenação intersetorial, criados já na lei que instituiu o PBF (Lei no 10.832/04), era um órgão colegiado, denominado Conselho Gestor Interministerial do Programa Bolsa Família, com a finalidade de formular e integrar políticas públicas. No entanto, como mostrado em Silva (2013), mecanismos desse tipo, por envolverem diretamente o alto escalão ministerial, embora sejam importantes instrumentos para a geração política de consenso e de estabelecimento de prioridades, são incapazes de dar materialidade à intersetorialidade. Em outras palavras, reuniões pontuais dos altos escalões ministeriais não garantem a construção da intersetorialidade, propriamente dita. É necessário que a missão de 
construção da intersetorialidade seja difundida pelas organizações e assumida por seus membros. Tal missão remete, assim, à importância de entender os mecanismos de delegação de poder, capacidade de liderança técnica e política e nível de engajamento da burocracia com as prioridades políticas deste tipo de agenda: de coordenação e de temática de política pública (aqui entendida como capacidade de politização da burocracia).

\section{O papel da delegação central, da importância da temática e de mecanismos de politização}

O conceito de politização da burocracia, utilizado neste artigo, difere dos normalmente empregados nos trabalhos acadêmicos nacionais, que em geral associam essa prática com um processo de utilização dos cargos de livre provimento para a nomeação de membros do partido político presidencial ou a ele associados (D’Araújo, 2013), característica, com alguma frequência, apontada como negativa. Entende-se, aqui, politização da burocracia como o processo de engajar a burocracia com as causas e temas prioritários da agenda governamental, processo no qual as burocracias são empoderadas, já que são envolvidas para além da atuação técnica, atuando politicamente e com forte interlocução com os políticos. Essa característica não só é desejável, como já é uma realidade em algumas burocracias de países da OCDE (Aberbach, Putnan e Rockman, 1981), quebrando a velha dicotomia entre burocracia e política. Dessa forma, devese pensar não em uma burocracia, mas em tipos de burocracia, com diferentes combinações de capacidade técnica e política.

O engajamento de todos os órgãos envolvidos em atividades de articulação intersetorial é essencial para o sucesso das relações de cooperação estabelecidas. $\mathrm{Na}$ administração pública, o corpo político é o grande responsável pela priorização do tema e sua disseminação por todo o governo. É uma atividade que exige liderança política e capacidade de percepção da importância da temática. Dadas algumas características inerentes à burocracia estatal, essa ação de engajamento e politização das equipes de trabalho não é atividade trivial e não demanda somente autoridade formal, sendo necessária uma grande coesão tanto para o comprometimento, quanto para a execução das atividades intersetoriais.

Vemos, no caso do PBF, uma importante atuação presidencial no sentido de disseminação da importância das políticas de combate à pobreza. Tal relação ficou evidente em diversas entrevistas. Já em sua campanha presidencial de 2002, Lula insistia em chamar a atenção da opinião pública para o problema da fome e da pobreza, e para a necessidade de enfrentálo mediante políticas públicas fortes, articuladas e inovadoras. Essa habilidade em despertar o interesse da sociedade e disseminar a temática foi importante e conseguiu repercutir no interior do governo e das burocracias governamentais. Cada vez mais a temática passou da elite política dirigente para os demais níveis hierárquicos da administração pública. A capacidade de mobilização popular de Lula transformouse em capacidade de politização da burocracia quando de sua chegada à Presidência. Politização nesse caso significa que "os funcionários públicos começam a assumir tarefas que anteriormente (e formalmente) poderiam ter sido consideradas políticas"2 (Peters e Pierre, 2004, p. 3). Essa capacidade de politização da burocracia seria crucial para o envolvimento dos ministérios com a temática do desenvolvimento social 
e a missão da intersetorialidade, principalmente em um contexto de chegada do PT no governo pela primeira vez. Nesse contexto a burocracia representaria, em tese, um obstáculo para novas orientações de trabalho e de políticas públicas.

O compromisso de burocratas com os valores e interesses da área política é geralmente visto como apenas mais um motivo para as dificuldades com as quais os ministros se deparam ao tentar gerenciar seus programas e seus ministérios. Isso é especialmente verdadeiro para os partidos que chegam ao governo depois de algum período na oposição e descobrem que existem relações de trabalho na burocracia que não os favorecem (Peters e Pierre, 2004, p. 3).

Outros trabalhos já salientaram a importância da liderança do Presidente Lula para o envolvimento das equipes de trabalho que constituíram o PBF (Monteiro, 2011). A ação de criar uma nova estrutura organizacional para trabalhar a temática do desenvolvimento social foi uma opção que permitiu a montagem de uma nova burocracia, diminuindo as possíveis barreiras corporativas e de cultura organizacional para a implementação do PBF. Criar uma nova figura organizacional, rompendo com redes tradicionais de serviços públicos, é apontado na literatura, também, como uma estratégia interessante para se permitir as transformações necessárias à coordenação intersetorial (DRAIBE, 2009). De maneira geral, a burocracia que se formou no MDS apresenta um forte engajamento com a temática, o que tem se refletido sobre seu desempenho e sobre sua capacidade de articulação intersetorial. Esse envolvimento foi recorrentemente destacado nas entrevistas:
Aqui na Senarc [Secretaria Nacional de Renda de Cidadania], eu noto uma qualidade muito boa dos técnicos que estão aqui. (...) É um time que tem um pouco daquela coisa do social. Eu que venho da área econômica, posso dizer que na área econômica é aquela burocracia rígida; aqui não, como se tem uma causa nobre, uma missão muito nobre, tudo que se faz se vê as consequências do outro lado, temos um time

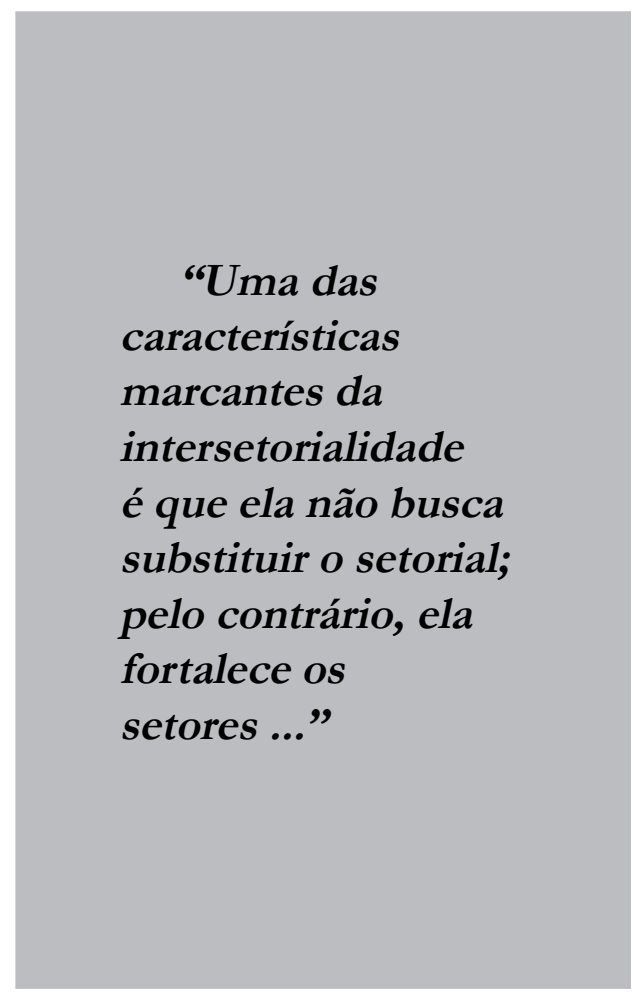

muito apaixonado. (Entrevista concedida pelo Diretor do Departamento de Benefícios da Senarc, Walter Emura, realizada em maio de 2012, na sede do MDS em Brasília-DF).

As proporções atingidas pela mobilização em relação à temática se consolidam como uma das maiores armas 
das ações governamentais de combate à pobreza. Um dos reflexos é a alta procura dos servidores federais por atuar no MDS, o que tem sido muito importante para o fortalecimento de suas capacidades gerenciais. Nos dizeres de Luciana Alves ${ }^{3}$ : "Hoje todo mundo quer vir trabalhar aqui no MDS, ainda que tenhamos algumas precariedades, mas já foi pior. (...) Quando nós começamos a trabalhar com o Bolsa Família, nós éramos em 8 pessoas. A equipe de benefícios tinha um computador, que nós usávamos em 4 pessoas".

\section{O processo de materialização da intersetorialidade no PBF}

O processo de engajamento e politização da burocracia analisado acima, desencadeou articulações cotidianas entre os burocratas federais para a criação de sistemáticas de coordenação e trabalho conjunto. A partir da análise das entrevistas dos servidores, mapeamos e desenvolvemos o modelo exposto abaixo. Consideramos ser esse modelo o processo de materialização da intersetorialidade no âmbito do Programa Bolsa Família, principalmente no que diz respeito às articulações entre os Ministérios da Saúde, Educação e o MDS. Descrito o ambiente de grande aderência política da temática, as relações intersetoriais já contariam com um ambiente organizacional e político favorável, dando início, assim, à materialização da intersetorialidade no âmbito do Executivo Federal.

O processo mapeado por esta pesquisa, a partir do resgate histórico da construção da intersetorialidade relatado pelos entrevistados, destaca que o elemento de partida seria a percepção governamental da importância da intersetorialidade (etapa 1). São inúmeros os exemplos de priorização de soluções intersetoriais, desde instrumentos formais, como a inclusão do princípio da intersetorialidade na própria lei que instituiu o PBF e a criação de um órgão colegiado para levá-la adiante, até explicações

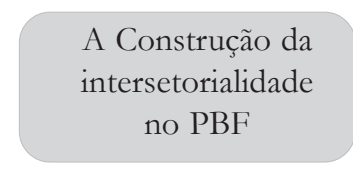

5) Práticas de Trabalho (geração de informalidades)
1) Percepção do desafio:
Intersetorialidade

2) Priorização/ Entrada na Agenda

\section{4) Empoderamento da Média Burocracia}

3) Construção de Capacidades
8) Formalização

Fonte: Elaboração própria.

Figura 1: O processo de materialização da intersetorialidade no PBF em nível federal 
institucionais que serão apresentadas ao longo do artigo. A etapa 2 seria o momento em que começam as primeiras reuniões e os primeiros debates, que se desdobrarão no estabelecimento de uma série de compromissos dos vários órgãos, os quais serão levados adiante na etapa 3 , em que serão construídas as capacidades (alocação de recursos humanos e financeiros, preparação das equipes de trabalho e dos seus ambientes de trabalho). A etapa 4 é o centro do arranjo intersetorial criado em torno do PBF, já que o engajamento das burocracias dos órgãos é o que fará a intersetorialidade materializar-se cotidianamente. Tão importante quanto a vontade política (envolvimento do Presidente e de seus ministros) é o engajamento das suas burocracias médias (escalão intermediário), que serão responsáveis por exercer o papel de agente e coordenador das relações entre os setores (mais adiante exploraremos melhor essa etapa).

Prosseguindo, há a intensificação dos relacionamentos entre as burocracias e a chegada pela primeira vez do processo aos executores das tarefas administrativas (etapa 5), o que vai gerar uma série de padrões de relacionamentos, calcados, em um primeiro momento, em traços informais e pessoais, dado o baixo controle inicial. Na etapa 6, busca-se, por meio de tarefa de aprendizagem coletiva, identificar quais experiências não estão funcionando, corrigindo-as, mas, principalmente, identificando os padrões de sucesso, descritos durante a etapa 7 , de modo a mapear a rotina de relacionamento e tentar suprimir as marcas pessoais, padronizando-as. Por fim, na etapa 8 , seriam feitos os debates entre as áreas para a construção de consenso em torno do que pode ser formalizado, momento crucial para a gestão do conhecimento e estabilidade da cooperação horizontal.
A etapa 1, marcada pela percepção do desafio da intersetoriliadade, tem emergido por inúmeras frentes. A intersetorialidade passa a ser um princípio basilar das políticas de desenvolvimento social, que passaram a ter maior destaque como objetivo governamental (SILVA, 2013). A busca pela intersetorialidade e pela integração de políticas sociais passa a ser uma estratégia para dar materialidade ao processo de debate público em torno da agenda do crescimento com diminuição das desigualdades sociais, que ganhou força durante a campanha presidencial de 2002, ao eleger o Presidente Lula e levar ao governo o Partido dos Trabalhadores. Fica claro que dar maior capacidade ao Estado de intervir sobre a agenda social passa por uma ampliação dos mecanismos de coordenação e integração de políticas, abrindo caminho para experimentações e inovações institucionais.

A segunda etapa também tem a ver com o papel do Presidente e do grupo político mais fortemente articulado a ele. De maneira geral, a liderança do Presidente e seu discurso de combate à pobreza refletem-se, em algum grau, sobre a mobilização dos ministros e de suas equipes para a valorização da temática do desenvolvimento social, gerando um ambiente favorável à cooperação e ao trabalho conjunto entre os ministérios. Percebe-se a presença do que Kingdon (1984) define como sendo a convergência necessária dos três fluxos que gerarão a Policy $W$ indow para a entrada de um tema na agenda governamental: os fluxos problems (construir uma política de desenvolvimento social, em que a intersetorialidade aparece como tema chave), proposals (aproveitamento e aprendizagem com as experiências anteriores de transferência condicionada de renda em Estados e Municípios, bem como 
as evoluções de práticas de gestão do próprio Governo Federal, como o Bolsa Escola e o Cadastro Único) e politics (discurso político mobilizador da temática do desenvolvimento social e do combate à pobreza).

Uma das características marcantes da intersetorialidade é que ela não busca substituir o setorial; pelo contrário, ela fortalece os setores, que podem, a partir dela, maximizar esforços e recursos escassos e promover intervenções mais complexas e especializadas. Essa característica é respeitada no PBF, já que o MDS não retira atribuições dos demais ministérios, não compete pelo mesmo recurso orçamentário (são recursos independentes), garantindo que não se comprometa a execução de outro programa social. Isso potencializa as etapas $2 \mathrm{e}$ 3, diminuindo possíveis conflitos e maximizando a utilização de recursos escassos.

Outra característica da etapa 3 (construção de capacidades) foi a rápida nomeação para cargos de direção no MDS de uma série de servidores da carreira de Especialista em Políticas Públicas e Gestão Governamental (carreira transversal de recrutamento meritocrático e técnico para a formação de um corpo qualificado de servidores que, dependendo da sua capacidade política e alinhamento ao governo, podem ocupar os postos estratégicos, em cargos de direção, que compõem parte dos chamados cargos em DAS - Direção e Assessoramento Superior). Em geral, os membros dessa carreira possuem altos níveis de remuneração e formação, além de possuir uma elevada capacidade de articulação entre si para a execução de políticas públicas, o que, partindo do fato de que eles estão em distintos ministérios, gera um grande potencial de articulação entre os órgãos e as políticas públicas, como veremos.
Por "empoderamento da burocracia média" entende-se o processo pelo qual será recrutado um grupo de servidores da burocracia para coordenar as ações, sendo o elo entre a alta burocracia (gabinetes ministeriais) e a burocracia operacional, como podemos ver mais claramente na "pirâmide organizacional da administração pública federal brasileira", apresentada na Figura 2. Ficou claro nas entrevistas que essa burocracia média que se forma tem sido empoderada, já que a estratégia governamental é dar a ela autonomia e meios políticos e organizacionais para gerar as relações de intersetorialidade. No presente caso, a burocracia média, em linhas gerais, será ocupada por servidores públicos que serão postos em função de chefia. Esse processo na administração pública segue uma lógica em parte diferente da lógica da administração privada, mesmo que essa diferença seja tênue, pois tão significativa como a capacidade gerencial é a capacidade política de engajamento à estratégia governamental (politização). Assim, esse processo de nomeação pode ser também um processo de cooptação da burocracia, o que tem efeitos distintos, porém um deles é dotar a organização de maior coesão e, portanto, maior capacidade de coordenação (SELZNICK, 1978) ${ }^{4}$. Ao cooptar parte da burocracia, há a abertura para o estabelecimento de um elo de coordenação entre duas formas de pensar: a dos dirigentes políticos e a dos burocratas e servidores públicos. Seria, pois, a abertura de fendas à suposta tese de recrudescimento dos anéis burocráticos.

Esse processo de empoderamento pode também gerar uma elite burocrática no posto de média chefia, uma espécie de oligarquização da burocracia. Essa elite teria alto nível de poder (dado a ela pelos 


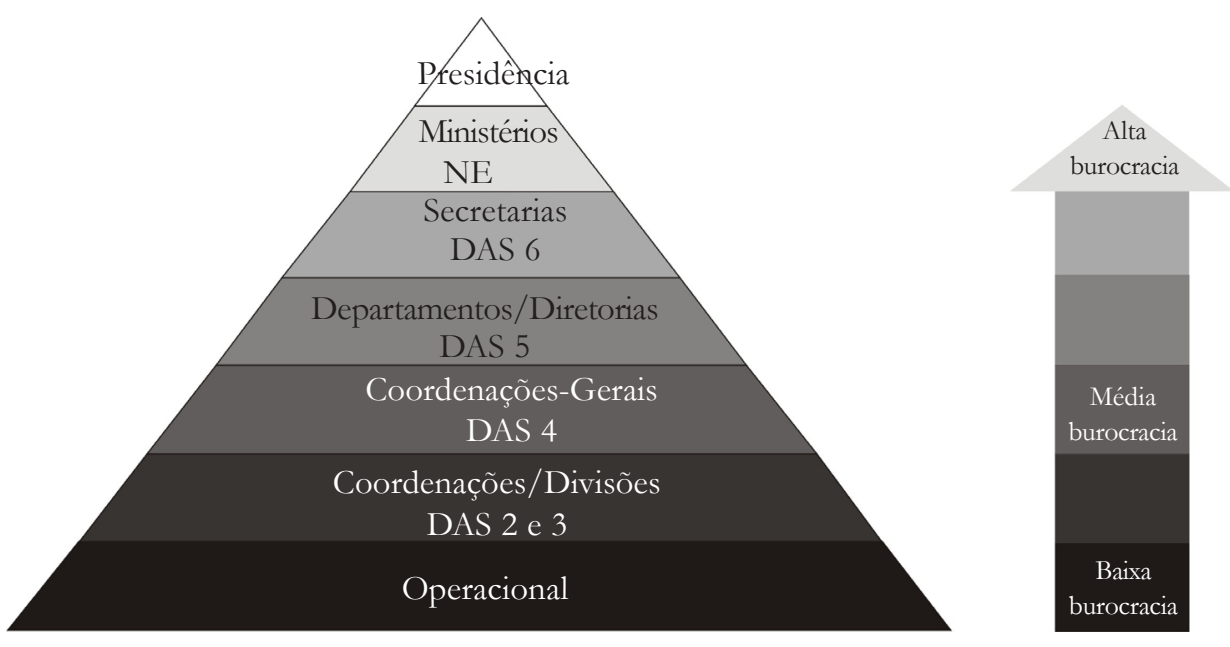

Fonte: Elaboração própria.

\section{Figura 2: Pirâmide Organizacional da Administração Pública Federal ${ }^{5}$}

processos de empoderamento a partir da nomeação/recrutamento para o posto de chefia), seria, em tese, homogênea (dada a alta concentração dentro de uma mesma carreira de burocratas) e com circulação por ambientes muito similares, o que a levaria a uma coesão interna maior ainda. A presença de redes informais de circulação e articulação, que podem ser potencializadoras de intersetorialidade, como veremos, pode também aumentar a possibilidade de comportamento autorreferenciado, levando áreas de forte potencial para o insulamento burocrático, tão identificado na cultura política do Executivo Federal (SCHNEIDER, 1995; Loureiro e Abrucio, 1999). Vemos, pois, que a média burocracia pode ser tanto um forte lócus de protagonismo e êxito das transformações como um forte obstáculo (voltaremos nesse ponto mais adiante).

Os ministérios setoriais envolvidos em questões horizontais são os que mais provavelmente serão afetados pelo fenômeno "nadar contra a correnteza", ou seja, pela estrutura vertical de elaboração e apresentação de relatórios e por requisitos verticais de accountability, que tendem a ser a norma em todos os ministérios e outros órgãos (BAKVIs, 2002). A pressão tende a ser mais sentida não no topo da hierarquia, mas nos níveis intermediários da gestão operacional e dos serviços corporativos. Além disso, entre os efetivamente envolvidos em projetos horizontais, percebe-se que os gargalos são mais acentuados nos níveis intermediários dos ministérios. Percebe-se que, na maioria dos ministérios, a horizontalidade não é levada muito a sério no nível operacional. (BAKVIs e Julliet, 2004, p. 78-79)

Como destacado no trecho, as burocracias, principalmente as médias, podem ser um obstáculo para as ações horizontais. Ou seja, não é nada comum a burocracia média ser uma aliada do esforço intersetorial, pelo contrário, na maioria das vezes 
não será. O nosso estudo de caso, entretanto, parece possuir condições razoavelmente próximas das que corresponderiam a um ambiente altamente propício para o engajamento e cooperação, como discorreremos ao longo deste artigo.

Sobre interferência política, aqui, temos uma equipe muito focada com objetivos e missões. Mas não há uma burocracia blindada; historicamente nós tivemos uma série de técnicos em posições de comando, mas que dialogam muito bem com o nível político. Eles têm uma capacidade de argumentação e de negociação acerca de problemas e restrições orçamentárias que não é todo lugar que tem. O nosso perfil de burocracia não é nem do tipo de burocrata puro que diz que está aí para fazer um trabalho técnico e ponto, nem do tipo político puro. Temos um equilíbrio interessante. (Entrevista realizada com o Diretor do Departamento de Benefícios da Senarc, Walter Emura, realizada em maio de 2012, na sede do MDS em Brasília-DF).

Se por um lado incorremos no risco de "oligarquização" da burocracia e insulamento burocrático, podendo levar a burocracia a portar-se como ponto de veto para as políticas públicas, por outro, o empoderamento da burocracia média abre oportunidades para a inovação da gestão e do padrão de intersetorialidade desenvolvido. A criatividade do corpo de servidores é estimulada, o que é um valor raro de ser alcançado em burocracias públicas, principalmente de países em desenvolvimento, como o Brasil (OCDE, 2010). A criatividade da burocracia, agregada à sua capacidade de articulação em rede, de fazer circular um grande fluxo de informações e conhecimentos, aliados à transferência de autonomia com mecanismos de accountability são aspectos decisivos para a conformação da etapa 5 , em que os próprios servidores criaram, através do ajustamento mútuo, um conjunto de práticas e de padrões informais de intersetorialidade e cooperação entre os distintos setores e órgãos do Executivo Federal.

As etapas 6 e 7 (seleção e descrição dos padrões informais) estão associadas à presença de uma cultura que deixa as boas práticas emergirem; elas são valorizadas, já que são orientadas pela ideia de passarem a ser formalizadas e disseminadas. A gestão da qualidade na gestão pública já nos chama atenção para a característica de padronização de atividades periódicas e constante monitoramento e análise do que vem sendo feito. Estimular um servidor público a pensar em padrões de processos, extraindo destes, portanto, suas características pessoais, não é tarefa fácil. Sobretudo quando se trata de práticas que foram acontecendo sob um contexto de grande informalidade e baixa rigidez procedimental, desde uma perspectiva incremental de tentativa e erro. Desse modo, a etapa 8, padronização, conta com a liderança de um servidor bastante experiente, seja em conhecer aspectos gerais de políticas públicas, seja em conhecer bem a própria secretaria; é, portanto, alguém que possui uma visão pragmática e geral. Esse líder estabelece conjuntamente com os servidores o processo de identificação, seleção e padronização das boas práticas, transmitindo às equipes a expertise que possui em manejar também os aspectos regimentais e legais.

Tudo isto (rotinas entre as equipes do MDS, MS e MEC) já está formalizado e a formalização foi posterior às experiências e rotinas das equipes. Uma 
das minhas funções, aqui, é escrever as portarias e atos normativos sobre o programa. E uma coisa muito interessante aqui, e que eu ainda não tinha encontrado em outro lugar, é que muitas normatizações e institucionalizações são decorrentes da experimentação. Muito dessa institucionalização seria a cristalização do que podemos chamar de melhores práticas. Então, assim, tentou-se uma coisa, não deu certo, tenta-se outra, o que deu certo já acaba virando um padrão e aí a gente escreve uma portaria a respeito disto. As únicas portarias que são anteriores são as portarias que determinam os fluxos de informação. Depois, todo o detalhamento e construção de como vai ser, fizemos primeiro na prática e depois cristalizamos, padronizamos. Hoje, todos os aspectos do programa e do cadastro já estão normatizados. E já está institucionalizado de direito, através das regras, portarias e atos normativos e de fato porque cristalizamos aquilo que já estava acontecendo no dia a dia. (Entrevista realizada com o Assessor da Secretaria Nacional de Renda de Cidadania - Senarc, Bruno Câmara, realizada em maio de 2012, na sede do MDS em Brasília-DF).

Os processos descritos levam à formação e formalização de padrões de cooperação intersetoriais com alto grau de legitimidade (a formalização vem expost e como forma de cristalização do conjunto de práticas) e eficácia, uma vez que surge baseada no fato concreto, já nasce com viabilidade assegurada. E, mais importante, os procedimentos e as pessoas responsáveis por eles são amplamente conhecidos. Não resta dúvida, também, de que a padronização assegura maior estabilidade à intersetorialidade formada, já que ela deixa de vincular-se a características pessoais e canais de comunicação organizacional restritos.

O ambiente de cooperação experimentado entre o MDS e outros ministérios por meio da Secretaria Nacional de Renda de Cidadania (Senarc) pode ser entendido a

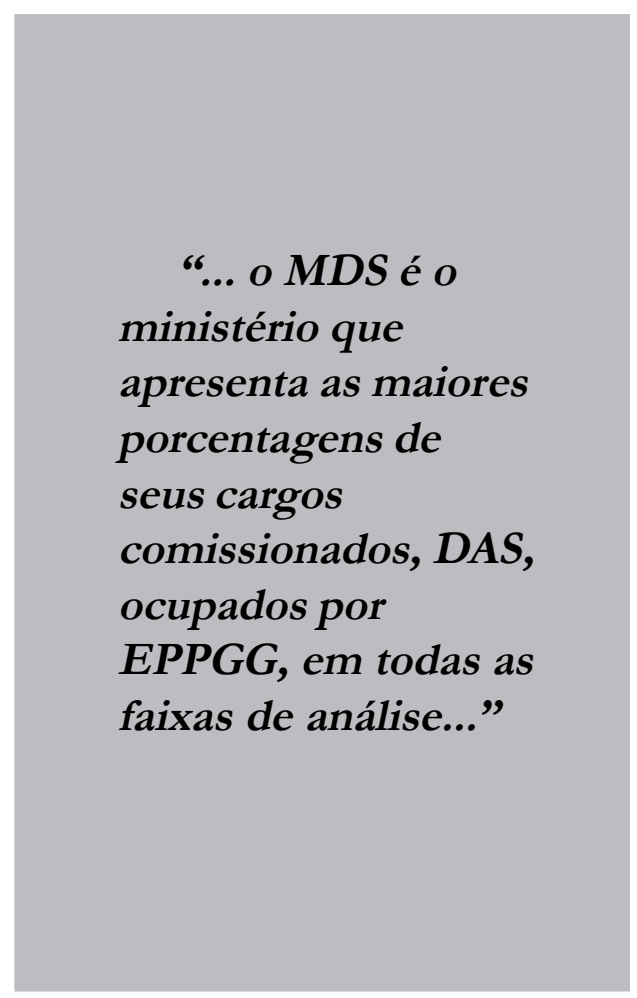

partir de um processo de retroalimentação. Ficou evidente nas entrevistas que, ao construir no interior da Senarc um corpo técnico qualificado, politizá-lo e empoderá-lo, colocando-o em posições gerenciais para liderar, a equipe ganha desempenho. Pouco a pouco, o desempenho da equipe começa a repercutir no próprio êxito e sucesso da política, o que gera ainda mais confiança e legitimidade dessas equipes de trabalho perante o restante do governo, levando a um aumento da adesão dos ministérios 
parceiros e dos engajamentos intersetoriais. Está formada, assim, uma estrutura de legitimação do processo de coordenação intersetorial.

Esse processo de legitimação da atividade de coordenação é favorecido e está fortemente calcado em redes informais, muito influenciadas pelos temas de interesse e pela atuação pregressa dos burocratas que compõem a média burocracia. A burocracia da Senarc conta tanto com servidores que já trabalham com o programa há muitos anos, alguns até mesmo antes da unificação de 2004, como com outros que foram chegando em diferentes momentos, quase todos trazendo para o posto para o qual são designados algum grau de expertise setorial e uma rede de relacionamento com burocratas de outros órgãos estratégicos. A formação de uma burocracia particular, tecnicamente forte, com razoável manutenção e pontualmente arejada com burocratas articuladores só é possível nesse caso fazendo-se forte utilização de carreiras horizontais, aqui, os Especialistas em Políticas Públicas e Gestão Governamental (EPPGG).

Essa particularidade da formação da burocracia da Senarc é decisiva para entendermos os dilemas e desafios da coordenação intersetorial. Um fato frequentemente apontado nas entrevistas foi a dificuldade de coordenação intraministerial. Ao contrário do que a análise da estrutura organizacional formal poderia nos induzir a pensar, por vezes a coordenação entre as secretarias de um mesmo ministério será mais débil do que a coordenação entre secretarias de ministérios distintos. Apesar de contar com mais mecanismos formais e, principalmente, hierárquicos de coordenação, a coordenação intraministerial pode não contar muitas vezes com a presença de redes informais facilitadoras e de pro- cessos de legitimação da atividade de coordenação. O que queremos dizer é que não bastam mecanismos formais e hierárquicos para explicar o êxito da coordenação. Há uma parte fundamental que diz respeito às características das burocracias: suas redes de relacionamento, os valores que compartilham e as experiências que trazem consigo. Assim, uma forte explicação para a reiterada dificuldade de coordenação entre a Senarc e a Secretaria Nacional de Assistência Social (SNAS), ambas do MDS, em comparação a atividades de coordenação interministerial, seriam as características de suas burocracias. A burocracia da Senarc compartilha valores e conta com redes informais que a aproximam mais de órgãos de outros ministérios do que do próprio MDS, já que muitos dos burocratas da Senarc vieram desses órgãos.

\section{O papel das carreiras horizontais do serviço público}

Nesta seção continuaremos a analisar o papel das redes informais e das articulações entre burocratas, que, no caso analisado, ganha reforços com a utilização estratégica da carreira de Especialista em Políticas Públicas e Gestão Governamental (EPPGG). Há um forte beneficiamento da Senarc, e recentemente da Sesep, em relação a essa carreira, principalmente na formação de sua média burocracia (nível gerencial). O que pode ajudar a entendermos a concentração inicial de EPPGG nesses órgãos é que esta é uma das poucas carreiras do serviço público federal com grande flexibilidade de alocação, o que a destaca em um processo de composição de uma burocracia nova. Porém, como veremos, a concentração aqui analisada é sui generis, mesmo quando comparamos com outras 
burocracias recentes, já que o MDS é o ministério que concentra mais EPPGG em cargos de livre provimento, fundamentalmente na composição da média burocracia.

Uma construção histórica da utilização e do papel dos EPPGG na formação da burocracia da Senarc passa por entendermos o papel-chave da liderança exercida por Rosani Cunha. Membro da carreira, Rosani foi chamada a coordenar os trabalhos da burocracia que se formava e que ainda se preparava para construir os mecanismos de coordenação e de implementação do PBF. O seu papel de liderança técnica e política foi frequentemente apontado pelos entrevistados, principalmente os mais antigos. Estava claro para eles que Rosani Cunha havia sido designada para a coordenação dos trabalhos pela sua capacidade técnica e sua habilidade política de coordenação, fundamentalmente as duas mais centrais para o êxito do PBF: a coordenação intersetorial e a coordenação federativa. A ex-secretária da Senarc, Rosani Cunha, possuía a expertise de coordenação intersetorial, dada sua experiência e atuação como gestora, o que lhe permitia habilidade de entendimento do funcionamento da administração pública federal, dando-lhe legitimidade. Porém, sua missão central era transformar sua experiência e habilidade de coordenação intergovernamental exercida pela sua atuação como secretária-executiva da Frente Nacional de Prefeitos (FNP) em instrumentos, mecanismos e sistemáticas de coordenação federativa no PBF.

A atuação de Rosani e de outros EPPGG que chegaram com ela significou consolidação da estratégia de utilização da carreira de EPPGG como forma de potencializar as capacidades de coordenação baseadas em competências técnicas, redes informais e experiências pregressas, ou seja, para além de mecanismos formais e hierárquicos. Hoje conseguimos identificar a presença dos gestores (como também são conhecidos os EPPGG) em todas as áreas da Senarc. O secretário e todos os seus quatro diretores de departamento são membros da carreira. A eles se somam um grande coletivo de EPPGG nomeados como coordenadores-gerais, coordenadores, e em diversas outras funções. Recentemente a formação da burocracia da Sesep, criada em 2011, também se beneficiou da incorporação de gestores.

Mediante uma análise simples de perfil de atuação de alguns desses gestores, podemos identificar de maneira clara a relação entre as características de suas experiências pregressas e de suas redes de relacionamento intraburocráticas com as características dos tipos de coordenação demandadas pelos postos que ocupam. Por exemplo, o Departamento de Benefícios, que tem de coordenar sistematicamente suas ações com as da Caixa Econômica Federal, agente operador do PBF, tem em Walter Emura, seu diretor, um EPPGG com experiência em órgãos da área econômica, estando vinculado anteriormente ao Ministério da Previdência Social, que possuía os mesmos desafios de coordenação com a Caixa para a implementação dos programas de seguridade social. Por sua vez, os gestores Daniel de Aquino Ximenes e Marcos Maia Antunes, antes de assumirem as funções de Diretor e Coordenador do Departamento de Condicionalidades, respectivamente, atuavam no Ministério da Educação, justamente na própria diretoria responsável pelo acompanhamento $\mathrm{da}$ condicionalidade de educação no PBF.

Fica, portanto, nítida a importância da utilização da carreira de EPPGG para aumentar as possibilidades de materialização da coordenação intersetorial. Segundo dados 
do Ministério do Planejamento (SEges, 2008), o MDS é o ministério que apresenta as maiores porcentagens de seus cargos comissionados, DAS, ocupados por EPPGG, em todas as faixas de análise ("DAS 5, 6, NE e equivalente"; "DAS 4"; "DAS 3, 2, 1 ou equivalente"), superando o próprio Ministério do Planejamento. Além da argumentação já abordada, seria possível pensar que, ao tratar-se da composição de uma burocracia em um órgão novo imbuído de grande desafio técnico (unificação dos programas de transferência e cobertura territorial do PBF) e de uma grande prioridade política (agenda da pobreza), seria evidente que não se poderia utilizar outra carreira que não fosse calcada em uma sólida formação técnica e um amplo conhecimento do funcionamento da administração pública e do processo de produção de políticas públicas.

Por outro lado, se retomarmos a tese dos potenciais riscos de oligarquização dessa elite burocrática, já anunciados, veremos que a utilização dos EPPGG também provoca impacto diferente sobre a força desse potencial. Sabemos da literatura de teoria das elites (Hollanda, 2011; Hopkins, 1978) que as oligarquias tenderão a ter comportamentos de corporativismo e autodefesa, podendo lutar mais pelos seus próprios interesses que pelos das políticas em que eles atuam. Além disso, carreiras para a composição de uma elite administrativa tecnocrática, como é a de EPPGG, podem levar a processos perversos de falta de cooperação com o corpo burocrático dos ministérios, o que em alguns contextos tem levado seus membros a serem tachados de arrogantes (CHEIBUB e Mesquita, 2001).

Para prevenir processos de elitização e autorreferenciamento, a sempre reiterada politização passa a ter papel fundamental, pois será útil para que os burocratas mantenham o foco na política e se engajem por meio de uma postura cooperativa. A horizontalidade da carreira é outra caraterística do EPPGG que também acabaria por atenuar as características potenciais do comportamento coorporativo, evitando possíveis processos de oligarquização, já que essa característica leva a uma dispersão dos membros da carreira por toda a administração pública federal, fenômeno muito interessante, já que contribui negativamente para processos de oligarquização e positivamente para esquemas de cooperação intersetorial.

Trabalhos que analisaram a carreira de EPPGG demonstraram que esta não possui identidades (corporativas) tão fortes como outras carreiras da administração pública federal (MACHADO, 2003), fato que não é necessariamente ruim, principalmente para missões intersetoriais. Podemos dizer, por outro lado, que os EPPGG possuem uma "relativa identidade" adquirida, em boa parte, pelo contato estreito que possuem com a Escola Nacional de Administração Pública (ENAP), principalmente durante a fase do curso de formação para a carreira, que é um dos mais longos do Governo Federal ${ }^{6}$, durando alguns meses e proporcionando contato intenso entre gestores, até mesmo em ambientes informais. Isso tem levado à criação de uma rede informal de relacionamento e circulação entre os gestores, fazendo com que eles estabeleçam importantes redes de diálogo e camaradagem (Cheibub e Mesquita, 2001).

No entanto, dada a horizontalidade da carreira (possibilidade de alocação em diversos órgãos da administração pública federal), os gestores, ao acionarem suas redes de relacionamento com colegas de 
carreira, poderão fazer indiretamente a circulação de informações entre os ministérios. A rede de relacionamento entre os membros da carreira pode representar uma importante teia intersetorial para, por meio desse ambiente informal, dar sustentabilidade a relacionamentos e processos efetivos de coordenação governamental e intersetorialidade. Destacamos abaixo um trecho de entrevista transcrita na dissertação de Machado (2003), em que um EPPGG deixa transparecer esse aspecto:

A principal coisa que a gente se diferencia é poder trabalhar em qualquer área federal. Essa mobilidade é muito importante porque a gente circula em cargos importantes pela esplanada e acaba construindo uma rede de pessoas e contatos que pode articular os diversos ministérios e posições, mas por outro lado não sei se isso enfraquece a consolidação da carreira (MACHADO, 2003, p. 107).

Como já citado, a dispersão dos EPPGG pelos diversos ministérios, sem a vinculação muito forte com um lócus organizacional, prejudica a consolidação da identidade da carreira (Machado, 2003). Entretanto, diminui as capacidades de articulação corporativista, tendendo a inviabilizar processos coorporativos de autodefesa e de criação de obstáculos para a implementação de novas visões. Enfim, o que podemos concluir, a partir do nosso estudo, é que a forte utilização de carreiras horizontais em processos de construção de intersetorialidade pode ser uma estratégia bastante interessante para os governos, dando maiores capacidades de materialização e construção de relacionamentos entre os setores.

\section{Considerações finais}

O caso analisado possui um conjunto de condições altamente favoráveis ao engajamento das burocracias e de seus dirigentes em processos de coordenação intersetorial. Sintetizamos tais condições a seguir.

1) A temática tem apelo e aderência social.

2) A liderança política é fortemente exercida.

3) O recrutamento político das burocracias para ascender a postos gerenciais é feito com mecanismos importantes de politização.

4) Os recursos orçamentários do programa são incrementados ano a ano, sendo um dos menos afetados pela política fiscal.

5) Os ministérios não concorrem por recursos financeiros dentro do esquema de cooperação.

6) Os ministros reconhecem a importância do programa e do seu engajamento.

7) As burocracias têm autonomia política.

8) As burocracias se beneficiam de carreiras horizontais e de alta solidez técnica.

9) Há a abertura para a experimentação e inovação.

10) O órgão coordenador da atividade intersetorial é recente, não possuindo uma cultura organizacional forte como barreira à mudança.

O envolvimento das burocracias conta com a possibilidade e a real utilização de carreiras horizontais. A rede de relacionamento entre os membros da carreira pode representar uma importante teia intersetorial, gerando um ambiente informal que dá sustentabilidade a relacionamentos e processos efetivos de coordenação governamental e intersetorialidade. Enfim, não sabemos se o caso, aqui analisado para o 
PBF, de maior alocação de EPPGG em um ministério novo e imbuído de missões prioritárias pode ser ou não uma tendência no Governo Federal, mas o que podemos concluir é que a forte utilização de carreiras horizontais em processos de construção de intersetorialidade pode ser uma estratégia bastante interessante para os governos, dando maiores capacidades de materialização e construção de relacionamentos entre os setores.

A conscientização, tanto das elites dirigentes dos ministérios (ministros e secretários de Estado), como da burocracia estatal, é um fundamento basilar para a eficácia de qualquer missão intersetorial perseguida. Por tratar-se de um tema bastante emergente, requerendo a construção de soluções inovadoras, a intersetorialidade difere de outras ações tradicionais de políticas governamentais. O sucesso da intersetorialidade seria causado mais pela capacidade de liderança política e de priorização da temática, e menos por um viés incremental e de transformações por inércia. Demanda, pois, se não uma quebra de paradigma, pelo menos uma nova orientação política que consiga superar a tradição de articulação "intradepartamental" e estanque da burocracia e dos órgãos da administração pública, bem como a produção de políticas setoriais fragmentadas.

Nesse propósito, a capacidade de liderança do corpo político é decisiva para a entrada da temática da intersetorialidade na agenda e a priorização por parte dos ministros também é essencial. Porém, tão ou até mais importante que o engajamento do corpo político será o engajamento das burocracias e a formação de coesão entre elas. A capacidade de mobilização popular de um governo deve transformar-se em capacidade de politização da burocracia. $\mathrm{O}$ caso do PBF nos faz pensar também em uma questão muito importante que por vezes pode-se desconsiderar. Tão fortes e frequentes como as divergências entre os ministérios podem ser as divergências intraministeriais.

Por fim, pode-se resumir esquematicamente a construção federal de intersetorialidade no PBF em cinco fenômenos fundamentais:

1) a construção de capacidades técnicas, através da formação de órgãos e de suas burocracias;

2) o empoderamento e a autonomia para experimentação, o que gera condições para que as equipes se engajem fortemente e inovem;

3) a estratégia de utilização das redes informais e das experiências pregressas dos burocratas como instrumentos de incremento e de maior materialização da coordenação;

4) o processo de legitimação técnica e política, tanto pelas relações interpessoais, quanto pelos resultados apresentados pelas burocracias;

5) o processo de fortalecimento institucional e formalização de padrões, em que as contribuições pontuais se unificam e ganham permanência no tempo, moldando e dando estabilidade às instituições.

(Artigo recebido em julho de 2013. Versão final em setembro de 2013). 


\section{Notas}

${ }^{1}$ Para maiores análises entre as transformações da dimensão institucional e organizacional do Executivo Federal provocadas pela emergência das políticas de desenvolvimento social nos últimos anos, ver Silva (2013).

${ }^{2}$ Do original: "politicization may also mean that public servants begin to take on tasks that formerly (and formally) might have been considered to be political."

${ }^{3}$ Luciana Alves de Oliveira é assessora de relações federativas da Secretaria Extraordinária de Superação da Extrema Pobreza.

${ }^{4} \mathrm{O}$ conceito de cooptação empregado neste artigo diferencia-se do conceito de cooptação mais difundido na ciência política brasileira, em que a cooptação é vista como algo pejorativo e que distorceria a atuação de determinados grupos. Baseamo-nos, aqui, no conceito derivado da obra de Selznick (1978), em que o processo é visto como uma espécie de "oxigenação" da organização, uma forma de construção de coordenação compatibilizando e complementando contribuições de diferentes grupos e indivíduos.

${ }^{5} \mathrm{O}$ objetivo desta figura não é o de marcar de maneira categórica quais níveis (DAS) são e quais não são entendidos como média burocracia. Essa delimitação é imprecisa na literatura, mas o que a figura nos ajudaria seria a pensar na média burocracia como os ocupantes dos cargos intermediários entre o nível tático e o nível operacional, portanto, aproximam-se dos DAS intermediários como o 4.

${ }^{6}$ A carreira de EPPGG é a carreira que possui a maior carga horária de curso de formação entre todas as carreiras do chamado "Ciclo de Gestão do Governo Federal" (composto, ainda, pelas carreiras de Analista de Finanças e Controle, Analista de Planejamento e Orçamento, Analista de Comércio Exterior e Técnico de Pesquisa do IPEA) segundo dados do Ministério do Planejamento, Orçamento e Gestão (disponível em: www.planejamento.gov.br, acessado em 16 de dezembro de 2012).

\section{Referências bibliográficas}

Abrucio, F. L; Loureiro, M. R. Política e burocracia no presidencialismo brasileiro: o papel do Ministério da Fazenda no primeiro governo FHC. Revista Brasileira de Ciências Sociais, vol.14, n.41. São Paulo,1999.

Adler lomnytz, L. Estrategias informales en organizaciones formales. In: Redes Sociales, Cultura y Poder: ensayos de antropología latinoamericana. FLACso, Sede México. M.A. Porrúa (México,1995).

Bacha, E. L.; Schwartzman, S. (organizadores) Brasil: a nova agenda social. Rio de Janeiro: LTC, 2011.

BAKvis, H.; Juillet, L. O desafio horizontal: ministérios setoriais, órgãos centrais e liderança. Cadernos ENAP. Brasília, 2004. 
BICHIR, R. M. Mecanismos federais de coordenação de políticas sociais e capacidades institucionais locais: o caso do Programa Bolsa Família [tese de doutorado]. Rio de Janeiro: Programa de doutorado em Ciência Política do Instituto de Estudos Sociais e Políticos, IESP/ UERJ, 2011.

Bogason, P. Changes in the Scandinavian Model. From Bureaucratic command to Interorganizational negociations. Public Administration Review, vol. 76, 335-354, 1998.

Bouckaert, G; Peters, B. G; Verhoest, K. . The coordination of public sector organizations: shifting patterns of public management. Palgrave Macmillan, 2010.

Bourgault, J. Horizontalité et gestion publique: questions, aperçus et exemples, Québec, Presses de l'Université Laval, 2002.

Carneiro, C. B. L; Costa, B. L. D; vasconcelos, m. Intersetorialidade e pobreza: implementação, coordenação e o legado de políticas prévias. Anais do VII Encontro da $A B C P, 4$ a 7 de agosto, 2010, Recife-PE.

Cheibub, Z.; Mesquita, V. A. B. Os Especialistas em Políticas Públicas e Gestão Governamental: avaliação de sua contribuição para políticas públicas e trajetória profissional. Texto para discussão, 43. Brasília: ENAP, 2001. 0.

Considine, M.; LeWIs, J.; AleXander, D.. Networks, Innovation and Public Policy: Politicians, Bureaucrats and the Pathways to Change inside Government. Palgrave Macmillan, 2009.

Cunill Grau, N. La intersectorialidad en el gobierno y gestión de la política social. In: Anais do X Congreso Internacional del CLAD sobre la Reforma del Estado y de la Administración Pública. Santiago - Chile, outubro, 2005.

D’Araujo, M. C. S. Political appointees and political parties in Brasil since 1990. VII Congreso Latinoamericano de Ciencia Política. ALACIP. Quito: Ecuador, 2013.

Draibe, S. M. A política social no período FHC e o sistema de proteção social. Tempo Social, novembro de 2003, p. 63-101, 2003.

. Programas de Transferências Condicionadas de Renda. In: Cardoso, F. H.; Foxley, A (editores). América Latina - Desafios da Democracia e do Desenvolvimento: Políticas Sociais para além da crise. Ed. Campus, Rio de Janeiro. p. 103-143, 2009.

Fenwic, T. B. Avoiding Governors: The Success of Bolsa Família. Latin American Research Review, Vol. 44, No. 1. Latin American Studies Association, 2009.

Hollanda, C. B. Teoria das Elites. Rio de Janeiro: Zahar, 2011.

Hopkins, T. K. O conceito de sistema de autoridade. In: CAMPOS, Edmundo (org.). Sociologia da burocracia. Rio de Janeiro: Zahar, 1978.

Kingdon, John., Agendas, alternatives, and public policies. New York, Harper Collins, 1984.

KLIJN, E. Redes de políticas públicas: una visión general. Tradução de "Policy Networks: An Overview" in Kickert, W. J. M. \& Koppenjan, J.F.; (eds). Managing Complex Networks. Sage, London, 1998.

Longo, F. Mérito e flexibilidade: a gestão das pessoas no serviço público. São Paulo: Fundap, 2007.

Machado, R. A. R. Problemas e impasses da carreira pública no Brasil, a experiência dos gestores governamentais na Administração Pública Federal [dissertação de mestrado]. Departamento de Ciência Política, Instituto de Filosofia e Ciências Humanas, UNICAMP, 2003. 
Marques, E. C. Redes Sociais e Permeabilidade do Estado: Instituições e Atores Políticos na Produção da Infraestrutura urbana no Rio de Janeiro [tese de Doutorado]. Departamento de Ciência Política, Instituto de Filosofia e Ciências Humanas, UNICAMP, 1998.

Martins, H. F. Fragmentação e Intersetorialidade: em busca de uma agenda da integração. In: Levy, E. \& Drago, P. A. (orgs.). Gestão Pública no Brasil Contemporâneo. FUNDAP. São Paulo, 2005.

Mcconaghy, D. Getting It Together: Joined-Up Knowledge and the Strategic Framework of Debate. Public Money \& Management Journal, February, 2007.

MDS. Sistema de Gestão de Condicionalidades do Programa Bolsa Família - Sicon/PBF: Manual Sicon Versão 4.0. Ministério do Desenvolvimento Social e Combate à Fome. Brasília, 2010. Monteiro, I. R. Integração de políticas sociais: um estudo de caso sobre o Bolsa Família [dissertação de mestrado]. Rio de Janeiro: Programa de Pós-graduação em História, Política e Bens Culturais do CPDOC/FGV, 2011.

Navarro, N. A Intersetorialidade como Modelo de Gestão das Políticas de Combate à Pobreza no Brasil: O Caso do Programa Bolsa Família no Município de Guarulhos [dissertação de mestrado]. São Paulo: Curso de Mestrado em Administração Pública e Governo da Escola de Administração de Empresas de São Paulo - EAESP/FGV, 2011.

Neri, M. A nova geração de políticas sociais. In: OLIVEIRA, F. B. (Orgs.), Política de Gestão Pública integrada. Rio de Janeiro: FGV, 2008.

Peters, G. Managing Horizontal Government. The Politics of Coordination. Research paper No 21. Ottawa: Canadian Centre for Management Development, 1998.

. Governing from the Center: The Search for Coordination and Coherence.

X RedGob Annual Meeting. University of Brasília. Brasília, 2012.

Peters, G.; PIERRE, J. Politicization of civil service. In: PETERS, G.; PIERRE, J. Politicization of the Civil Service in Comparative Perspective: The quest for control. London: Routledge, 2004. Pollitt, C.. Joined-up Government: a Survey. Political Studies Review: 2003, vol. 1, p. 34 49, 2003.

QuinHÕEs, T. A.; FAVA, V. M. D. Intersetorialidade e transversalidade: a estratégia dos programas complementares do Bolsa Família. Revista do Serviço Público, vol.61. ENAP. Brasília, 2010.

Repetto, F.. Coordinación y gestión pública integral en América Latina: notas conceptuales. In: Reflexões para Ibero $\triangle$ América: Planejamento Estratégico. ENAP. Brasília, 2009.

Santos, W. G. Cidadania e Justiça. Rio de Janeiro: Ed. Campus, 1970.

Schneider, B. R. A Conexão de Carreira: uma Análise Comparativa de Preferências e Insulamento Burocrático. Revista do Serviço Público, ano 46, v. 119, n. janeiro, 1995.

Schwartzman, S. As causas da pobreza. Editora FGV. Rio de Janeiro, 2004.

SChWELla, E. Inovação no governo e no setor público: desafios e implicações para a liderança. Revista do Serviço Público. Brasília 56 (3): 259-276 Jul/Set, 2005.

SEges, Secretaria de Gestão. Gestão da Carreira de Especialista em Políticas Públicas e Gestão Governamental. Ministério do Planejamento, Orçamento e Gestão, Brasília, 2008. 
SELZnick, P. Cooptação: um mecanismo para a estabilidade organizacional. In: CAMPOS, Edmundo (org.). Sociologia da burocracia. Rio de Janeiro: Zahar, 1978.

SERRA, A. La gestión transversal: expectativas y resultados. In: IX Congreso Internacional del CLAD sobre la Reforma del Estado y de la Administración Pública, 2 - 5 Nov. Madrid, España, 2004.

Silva, L. A. L. A emergência da intersetorialidade para a análise de políticas públicas. Anais do Seminário Nacional de Sociologia e Política. Universidade Federal do Paraná, 26 a 28 de setembro, Curitiba-PR, 2011. - A construção federal da intersetorialidade na política de desenvolvimento social bra sileira: O caso do Programa Bolsa Família [dissertação de mestrado]. São Carlos: Programa de Pós-graduação em Ciência Política. Universidade Federal de São Carlos, UFSCar, 2013. 


\title{
Resumo - Resumen - Abstract
}

\author{
Mecanismos da construção federal da intersetorialidade no Programa Bolsa Famí \\ lia: o papel das burocracias \\ Lucas Ambrózio Lopes da Silva
}

São descritos e analisados os mecanismos pelos quais a intersetorialidade é construída no Programa Bolsa Família (PBF) no nível federal. Embora a tarefa de conferir intersetorialidade ao programa seja compartilhada entre União e Municípios, principalmente, este trabalho enfocará a dinâmica de ação do Governo Federal, procurando entender como este tem construído a intersetorialidade. São apresentados mecanismos organizacionais e estratégias políticas mobilizadas com distintas consequências sobre o elevado grau da instersetorialidade construída. A atuação do Governo Federal vai muito além da formulação e do lançamento das diretrizes para o programa. Entre os distintos mecanismos e estratégias descritos, um deles destaca-se: a forte capacidade de mobilização e empoderamento de uma sólida burocracia, com alto potencial de coordenação intersetorial e alto compromisso político com os objetivos do programa. Analisase como os elementos dessa escolha e desse processo de empoderamento da burocracia, principalmente da burocracia de nível médio (nível hierárquico intermediário), têm levado à superação de obstáculos concretos e potenciais, imprimindo elevado nível de intersetorialidade ao PBF no que diz respeito à ação do Governo Federal, que também tem exercido poder de indução nos governos subnacionais.

Palavras chave: Programa Bolsa Família; intersetorialidade; burocracia

\section{Mecanismos de la construcción federal de la intersectorialidad en el Programa Bol sa Família: el rol de las burocracias \\ Lucas Ambrózio Lopes da Silva}

Se describe y analiza los mecanismos por los que la intersectorialidad se construye en el Programa Bolsa Família (PBF). Aunque la tarea de implementar el programa intersectorialmente sea compartida entre el gobierno federal y los municipios, sobre todo, este trabajo se centrará en la acción dinámica del gobierno federal, buscando comprender cómo se ha logrado efectivamente intersectorialidad. Son presentados mecanismos organizacionales y estrategias políticas movilizadas con diferentes consecuencias sobre el grado de la instersectorialidad construida. Así quedará claro que el papel del gobierno federal va más allá del diseño y puesta en marcha de las directrices para el programa. Entre las estrategias más notables destacaremos la fuerte capacidad de movilización y el empoderamiento de una sólida burocracia, con un alto potencial para la coordinación intersectorial y de alto compromiso político con el tema del programa. Es analizado como elementos de elección y de este proceso de empoderamiento de la burocracia ha llevado a la superación de obstáculos concretos y potenciales, lo que lleva el PBF a poseer alto nivel de intersectorialidad, en cuanto a la acción del gobierno federal, que también ha ejercido poder de inducción de los gobiernos subnacionales.

Palabras clave: Programa Bolsa Familia; intersectorialidad; burocracia 
Mechanisms of federal intersectoriality building in the Bolsa Família Program: the role of bureaucracies

Lucas Ambrozio Lopes da Silva

This paper describes and analyses the mecanisms by which intersectoriality is built in the Bolsa Família Program. Although intersectoriality comprises both the federal and municipal governments, this paper focuses on the dynamic action of the former, seeking to understand how it has effectively built intersectoriality in the Bolsa Família Program. It presents the organizational mechanisms and strategies that have different consequences for the degrees of intersectoriality. The findings point that the federal government goes far beyond designing and launching the guidelines for the Program. The strong capacity for mobilization and the empowerment of a strong bureaucracy with high potential for intersectoral coordination and high political commitment to the Bolsa Família Program theme are noteworthy. Further, the process of bureaucracy empowerment, especially at the mid-level of hierarchy, has led to the overcoming of concrete and potential hurdles for the Program. Such empowerment has confered high intersectoriality to the Program and led subnational governments to follow the federal agenda.

Keywords: Bolsa Família Program; intersectoriality; bureaucracy

Lucas Ambrózio Lopes da Silva

É doutorando em Administração Pública e Governo pela Escola de Administração de Empresas da Fundação Getúlio Vargas (EAESP/FGV) e mestre em Ciência Política pela Universidade Federal de São Carlos (UFSCar). Atualmente é pesquisador da Fundação Getúlio Vargas. Contato: lucasambrozio@yahoo.com.br 